\title{
The effect of Roux-en-Y gastric bypass in the treatment of hypertension and diabetes
}

\section{O efeito da derivação gástrica em $Y$ de Roux no tratamento da hipertensão e do diabetes}

Giulia Marchetti ${ }^{1}$ id; André Orsini Ardengh${ }^{1}$; Patrícia Colombo-Souza ${ }^{2}$; Paulo Kassab, TCBC-SP3; Wilson Rodrigues Freitas-Jr, TCBC-SP3; ELIAS JIRJOSS ILIAS, TCBC-SP3.

\section{A B S T R A C T}

\begin{abstract}
Introduction: obesity has become a public health problem in Brazil and worldwide, due to its high prevalence. It is considered a risk factor for systemic arterial hypertension (SAH) and type 2 diabetes mellitus T2DM. Although lifestyle changes can control and even achieve complete T2DM remission, most patients have difficulty controlling blood glucose. Recent studies show that the Roux-en-Y gastric bypass (RYGB) is efficient for weight loss and control of T2DM and SAH in obese individuals. Objective: to analyze the effect of the RYGB technique on the control and treatment of comorbidities related to obesity. Method: this is a retrospective cohort study, with information obtained from the review of medical records, with data collection in the pre and postoperative period of patients undergoing bariatric surgery. We selected those with T2DM and SAH for the study. Results: 252 patients underwent RYGB in the service. Seventynine (31.3\%) had T2DM and 64 had SAH associated with T2DM. Regarding T2DM and SAH, 37.9\% and 43,7\%, respectively, showed total remission of the disease after surgery. There was a reduction in the postoperative use of Metformin, insulin / Gliclazide, Propranolol, Losartan and Hydrochlorothiazide in $62 \%, 10.1 \%, 100 \%, 26.5 \%$ and $22.8 \%$ of patients, respectively. Conclusion: the RYGB technique is effective in the remission of T2DM and SAH. Even in cases where there was no total remission of the diseases, there was a significant drop in the use of medicines used for their treatment.
\end{abstract}

Keywords: Bariatric Surgery. Diabetes Mellitus. Hypertension. Obesity.

\section{INTRODUCTION}

$\mathrm{T}$ he increase in the prevalence of obesity has become a public health problem in Brazil and in the world ${ }^{1,2}$, mainly because it is a critical risk factor for metabolic diseases, such as dyslipidemia, Systemic Arterial Hypertension (SAH), and type-2 Diabetes Mellitus (T2DM). Although lifestyle changes, with weight loss induced by diet, exercise, and medical therapy can result in good control and even remission ${ }^{3-5}$ of T2DM, most patients have difficulty in sustained control of their blood glucose ${ }^{3}$. The same happens with $\mathrm{SAH}$, which has had weight loss as an initial treatment for a long time ${ }^{6-8}$, whose management is also challenging.

Bariatric surgery is the most efficient method for weight loss and for the control of comorbidities in obese patients. Current literature has shown that, in patients with T2DM, the remission rate varied between $24 \%$ and $95 \%$ in two years, depending on type of operation, definition of remission, and type of enrolled individuals ${ }^{3,4,9-11}$. In patients with arterial hypertension associated with obesity, some studies have shown that bariatric surgery was responsible for a reduction in the use of antihypertensive medications and better control of blood pressure ${ }^{4,10,12}$.

There is no doubt that surgery is a good therapeutic option for the control and treatment of comorbidities in obese patients. However, studies still lack regarding the class and quantity of medications used to obtain control of T2DM and SAH in the

1 - Faculdade de Ciências Médicas da Santa Casa de São Paulo, Medicina - São Paulo - SP - Brasil 2 - Universidade Santo Amaro, Pesquisa e Extensão - São Paulo - SP - Brasil 3 - Irmandade de Misericórdia da Santa Casa de São Paulo, Cirurgia Geral - São Paulo - SP - Brasil 
preoperative period and the evolution of these patients in the postoperative period.

The objective of the study is to analyze the effects of Roux-en-Y gastric bypass (RYGB) on the control and treatment of obesity-related comorbidities.

\section{METHODS}

This is a retrospective cohort study of patients consecutively treated at the General Surgery Department of the Irmandade da Santa Casa de Misericordia de São Paulo. The study was approved by the Ethics in Research Committee of the Faculty of Medical Sciences of Santa Casa de Sao Paulo (opinion 3,978,397). The data survey covered the period between January 1998 and December 2019.

The study included patients between 20 and 59 years old, of both sexes, with T2DM for at least two years, who underwent bariatric surgery at the service. All were submitted to RYGB. We excluded from the study the patients for whom it was not possible to maintain follow-up as to the variables analyzed. We evaluated sex, age, presence of T2DM, associated SAH, drugs used before and after the operation (Captopril, Enalapril, Losartan, Propranolol, Amlodipine, Hydrochlorothiazide, Glibenclamide, Metformin, Glylazide, Insulin, Simvastatin, Polyvitamins and Anxiolytics), and Body Mass Index (BMI).

\section{SAMPLE}

The sample consisted of 252 patients who underwent bariatric surgery at the service. Of these, 79 had type-2 diabetes in the preoperative period, 64 having both T2DM and SAH.

\section{VARIABLES}

The diagnostic criteria for preoperative T2DM were in accordance with the consensus of the American Diabetes Association (ADA) ${ }^{13,14}$, assessed by fasting glycemia, glycated hemoglobin ( $\mathrm{HbA} 1 \mathrm{c})$, and glucose tolerance test. We evaluated and classified hypertension by the periodic measurement of blood pressure during outpatient assessments, according to the $7^{\text {th }}$ Brazilian Guidelines for Hypertension. The weight loss of each patient was in accordance with the Body Mass Index Classification.

We recorded the number of medications used by each patient before and after the surgical procedure, to compare their need of use between both moments.

We determined the initial BMI on the day before the surgical procedure, and defined the final value after two years of follow-up.

The outcome of total T2DM remission was according to the ADA criteria ${ }^{15}$ : Fasting Glucemia < 100 $\mathrm{mg} / \mathrm{dL}$ and $\mathrm{HbA} 1 \mathrm{c}<6.0 \%$ without medication. Total remission of Hypertension was defined as the maintenance of normal blood pressure values according to the criteria of the $7^{\text {th }}$ Brazilian Guidelines on Hypertension without medication. Patients were diagnosed as in complete remission after two months of sustained postoperative laboratory follow-up, according to these definitions.

\section{FOLLOW-UP}

Patients were seen at the outpatient clinic three weeks after discharge from the procedure for clinical evaluation and decisions on further management with their respective attending physicians. All were reassessed monthly in the first quarter and then quarterly until the second year of follow-up. All patients included in the survey had at least six months of follow-up in the postoperative period before data collection and were followed for two years.

\section{STATISTICAL ANALYSIS}

We used the Mann-Whitney test to analyze the differences between the patients' ages and sex, the paired t test to verify changes in BMI before and after the surgical procedure, and the McNemar test to assess the presence of Diabetes and SAH before and after the operation. The level of significance was set at 0.05 , or $5 \%$.

\section{RESULTS}

During the study period, 252 patients underwent bariatric surgery at the service. Of these, 79 (31.3\%) had type-2 diabetes, and 64 had associated systemic arterial 
hypertension. Bariatric surgery was effective in reducing both T2DM and SAH.

The variables sex and age did not display significant statistical relevance in the resolution of T2DM and SAH (Table 1).

Table 1. Diabetic patients who underwent Roux-y bypass at Santa Casa Santa Casa de Misericórdia de São Paulo, according to sex and age (years) FCMSCSP, 2019

\begin{tabular}{lc}
\hline Female $(n=74)$ & Male $(n=5)$ \\
\hline Average $=50.1$ & Average $=44.0$ \\
Average $=51.0$ & Median $=43.5$
\end{tabular}

Standard Deviation $=9.7 \quad$ Standard Deviation $=3.16$

Mann-Whitney Test $\quad$ Calculated $=1.388$
$p=0.0825$

With regards to the medications used for T2DM, there was a $62 \%$ reduction in the use of Metformin in the postoperative period and a $10.1 \%$ reduction in the use of both insulin and Gliclazide (Table 2). When analyzing SAH medications, we observed a $100 \%$ reduction in the use of Propranolol, a $26.5 \%$ reduction in the use of Losartan, and a $22.8 \%$ reduction in Hydrochlorothiazide. However, there was a $3.7 \%$ increase in the use of angiotensinconverting enzyme (ACE) inhibitors (Table 2).

Table 2. Used medications by diabetic patients and those with hypertension who underwent Roux-y bypass at Santa Casa Santa Casa de Misericórdia de São Paulo, according to sex and age (years) FCMSCSP, 2019.

\begin{tabular}{lcccc}
\hline Drugs & Before & After & \% Before & Reduction\% \\
\hline SAH & & & & \\
\hline Captopril & 12 & 15 & 15.2 & +3.7 \\
Enalapril & 10 & 6 & 12.6 & -5.0 \\
Losartan & 30 & 9 & 37.9 & -26.5 \\
Propranolol & 2 & 0 & 2.5 & -100.0 \\
Amlodipine & 9 & 3 & 11.4 & -7.6 \\
HCTZ & 27 & 9 & 34.2 & -22.8 \\
\hline DIABETES & & & & \\
\hline Glibenclamide & 7 & 2 & 8.9 & -6.4 \\
Metformin & 55 & 12 & 77.8 & -62.6 \\
Glylazide & 11 & 3 & 13.9 & -10.1 \\
Insulin & 11 & 3 & 13.9 & -10.1 \\
\hline OTHERS & & & & \\
\hline Simvastatin & 19 & 4 & 24.0 & -21.0 \\
Polyvitamins & 3 & 35 & 3.8 & +40.5 \\
Anxiolytics & 4 & 5 & 5.1 & +1.3 \\
\hline
\end{tabular}

When analyzing the BMI before and after the operation, we found a statistically significant reduction after the procedure (Table 3 ).

Table 3. BMI of the patients who were operated, before and after the Roux-y bypass, at Santa Casa Santa Casa de Misericórdia de São Paulo, according to sex and age (years) FCMSCSP, 2019

\begin{tabular}{cc}
\hline BMI Preoperative & BMI Postoperative \\
\hline Average $=50.0$ & Average $=33.2$ \\
Median $=48.1$ & Median $=32.3$ \\
Standard deviation $=10.1$ & Standard deviation $=5.86$ \\
\hline Paired t-test & $\mathrm{p}<0.0001$ Before $>$ After \\
\hline
\end{tabular}

Of the 79 patients with T2DM preoperatively, 30 (38.0\%) had complete remission of the disease after the operation (Table 4).

Table 4. Patients before and after undergoing Roux-y bypass at Santa Casa Santa Casa de Misericórdia de São Paulo, according to the presence of diabetes FCMSCSP, 2019.

\begin{tabular}{cccc}
\hline Diabetes/Before & \multicolumn{2}{c}{ Diabetes/After } & Total \\
\cline { 2 - 3 } Yes $(79)$ & Sim & Não & \\
No (O) & 49 & 30 & 79 \\
Total & 0 & 0 & 0 \\
\hline McNemar Test & 49 & 30 & 79 \\
\hline
\end{tabular}

As for Arterial Hypertension, of the 64 patients with the disease, 28 went into complete remission after surgical treatment, with a reduction of $43.7 \%$ (Table 5 ).

Table 5. Patients with hypertension and diabetes before and after undergoing Roux-y bypass at Santa Casa Santa Casa de Misericórdia de São Paulo, according to sex and age (years) FCMSCSP, 2019.

\begin{tabular}{cccc}
\hline HAS/Before & \multicolumn{2}{c}{ HAS/After } & \multirow{2}{*}{ Total } \\
\cline { 2 - 3 } & \multicolumn{2}{c}{ Yes } & No \\
Yes (64) & 36 & 28 & 64 \\
No (15) & 0 & 15 & 15 \\
Total & 36 & 43 & 79 \\
\hline \multirow{2}{*}{ McNemar Test } & \multirow{2}{*}{$\mathrm{p}<0.0001 *$} & Reduction \\
& & $43.75 \%$ \\
\hline
\end{tabular}

\section{DISCUSSION}

Weight loss and fat reduction after bariatric surgery is already proven in the medical literature. The Swedish Obese Subjects study ( $n=4,047 ; B M l>34$ kg/ $\mathrm{m}^{2}$ ) showed a significant advantage of this procedure over non-surgical weight control ${ }^{16}$. After 20 years, the average total loss of body weight was $26 \%$ after RYGB, 
18\% after Sleeve Gastrectomy, 13\% after adjustable gastric banding, and $1 \%$ after non-surgical treatment. For this reason, we opted for RYGB for our patients who had a surgical indication for the treatment of morbid obesity.

In addition to weight loss, there is an important impact on metabolic diseases. Metabolic syndrome is defined as the simultaneous occurrence of abdominal obesity, hyperglycemia, dyslipidemia, and hypertension, being an important risk factor for the development of T2DM and cardiovascular diseases. Obesity surgery improves, even if partially, the metabolic syndrome in at least one of the three components, hyperglycemia/type2 diabetes, hypertension, and dyslipidemia, reducing the risk of events such as myocardial infarction and ischemic strokes by about $15 \%^{1}$. This is due to changes in neuroendocrine mechanisms mediated by glucagon-like peptide 1 (GLP-1) and changes in intestinal physiology, exerting a regulatory effect under glycemic control, regardless of weight loss ${ }^{17-20}$.

Although fasting GLP-1 levels generally do not change in the postoperative period, diet-related GLP-1 =secretion has been shown to gradually increase in the first two days after the operation, with increasing levels in the first six months ${ }^{14,21}$. This neuroendocrine mechanism results from the accelerated gastric emptying due to the absence of the pylorus and the increase in the levels of circulating bile acids ${ }^{22,23}$. Consistent with this hypothesis, studies have associated bile acid and GLP-1 responses, stimulated by food intake, four months after RYGB ${ }^{21,23}$ However, it has been shown that the contribution of the higher levels of bile acids to the secretion of GLP-1 or the effects of RYGB are probably late-development mechanisms ${ }^{13,21,24}$

As for T2DM, conservative treatments such as lifestyle modification, weight loss induced by diet, exercise, and medical therapy demonstrated significant glycemic control and even remission $3,5,11$. However, most patients undergoing this treatment modality have difficulty in obtaining sustained glycemic control ${ }^{3}$. A randomized study followed 60 patients for five years, and eight of the 15 subjects (53.34\%) in the RYGB group developed recurrent diabetes after reaching remission ${ }^{25}$. Even so, they observed that the proportion of patients without diabetes at five years was higher in the surgical group than in the drug-treatment-only group (50\% versus $0 \%$ ). The same was observed in multicenter studies that evaluated the remission of diabetes in patients undergoing different surgical procedures in the short and long term. RYGB led to remission of $83 \%$ in the short term ${ }^{26}$ and $60.2 \%{ }^{27}$ in a seven-year period, becoming the best surgical modality for the treatment of T2DM.

A French case-control study included more than 30,000 patients in a six-year follow-up. Those who underwent bariatric surgery were more likely to discontinue (50\% versus $9 \%$ ), and less likely to start ( $1.4 \%$ versus $12 \%)$, antidiabetic medications compared with obese patients who were not operated ${ }^{28}$. We saw the same pattern in our case series, with a $62 \%$ reduction in the use of Metformin in the postoperative period and a $10.1 \%$ reduction in both insulin and Gliclazide.

Another factor to be considered is the measurement of Peptide $\mathrm{C}$. The improvement of pancreatic beta cell function and insulin resistance in patients undergoing RYGB is closely related to the levels of Peptide C (PC) measured in the preoperative fasting. Studies indicate that patients with obesity and T2DM with preoperative $P C>1 \mathrm{ng} / \mathrm{mL}$ showed significant improvements after RGYB compared with patients with $\mathrm{PC} \leq 1 \mathrm{ng} / \mathrm{mL}^{29}$. Thus, although we did not evaluate $\mathrm{PC}$ in our study, it is considered a good marker for predicting surgical prognosis in patients with obesity and T2DM.

In the case of Systemic Arterial Hypertension, $43.7 \%$ of patients undergoing RYGB achieved total remission in two years of follow-up. These results were very similar to a cohort study conducted in Norway, which compared 932 obese patients who underwent bariatric surgery (92\% RYGB; 8\% Sleeve Gastrectomy) and 956 patients treated clinically, regarding the remission of arterial hypertension. At an average followup of 6.5 years, patients treated surgically had a higher probability of remission (31.9\% versus $12.4 \%$ ) and a lower probability of a new onset of SAH (3.5\% versus $12.2 \%)^{30}$

Obesity plays a significant role in the pathophysiology of SAH. The physical compression of the kidneys by fat activates the renin-angiotensinaldosterone system and the central nervous system, increasing sodium reabsorption, impairing natriuresis, 
thus causing hypervolemia. Over time, this mechanism causes a chronic kidney injury that perpetuates and worsens $\mathrm{SAH}^{31}$. We also know that abdominal fat is the first to be eliminated with weight loss after bariatric surgery and this is probably one of the mechanisms of hypertension remission, since it decreases abdominal pressure on the kidneys, deactivating the reninangiotensin-aldosterone system.

Even in patients in whom hypertension remission was not completely possible, we observed a reduction in the use of antihypertensive drugs. In our series, when analyzing the medications for $\mathrm{SAH}$, we noticed a $100 \%$ reduction in the use of Propranolol, a $26.5 \%$ reduction in the use of Losartan, and a $22.8 \%$ reduction in the use of Hydrochlorothiazide. However, there was a $3.7 \%$ increase in the use of ACE inhibitors, totaling a reduction of $35.4 \%$ in the total number of medications. The GATEWAY study, of 100 patients with hypertension and obesity, demonstrated that patients undergoing RYGB associated with medical therapy had a reduction of more than $30 \%$ in the use of antihypertensive drugs versus medical therapy alone ${ }^{32}$, showing good pressure control in these patients. This way, we were able to observe that, in our series, RYGB influenced not only the total remission of T2DM and $\mathrm{SAH}$, but also their partial control.

Our work has limitations that must be considered. As this is not a multicenter study, the sample size was limited by the number of patients seen at the services, so we decided not to perform a sample calculation. In addition, the duration of patients followup (two years) was relatively short, requiring an additional three-year follow-up to observe the real control of these comorbidities, the remission rate after a longer period, and the long-term effects of surgery. Given the morbidity of the procedure, our results do not imply that all patients with T2DM or SAH with characteristics similar to those included in our study should undergo bariatric surgery. However, we conclude that RYGB represents an additional option to help achieve control of these comorbidities by improving the metabolic and inflammatory profile of these patients.

Bariatric surgery is effective in solving T2DM and $\mathrm{SAH}$. Even in cases where there was no complete remission of the disease, there was a significant drop in the use of specific medication.

\title{
R E S U M O
}

\begin{abstract}
Introdução: a obesidade tornou-se problema de saúde pública no Brasil e no mundo, devido à alta prevalência. É considerada fator de risco para doenças metabólicas, como hipertensão arterial sistêmica (HAS) e diabetes Mellitus tipo 2 (DM2). Embora a modificação do estilo de vida possa controlar e até levar à remissão total do DM2, a maioria dos pacientes tem dificuldade em controlar a glicemia. Estudos recentes mostram que a derivação gástrica em Y de Roux (RYGB) é eficiente para a perda de peso e o controle de comorbidades em pacientes obesos. Objetivo: analisar o efeito da técnica RYGB no controle e tratamento de comorbidades relacionadas à obesidade. Método: trata-se de estudo de coorte retrospectivo, com informações obtidas pela revisão de prontuários, com coleta de dados no pré e pós-operatório de pacientes submetidos a cirurgia bariátrica. Selecionamos para o estudo aqueles com DM2 e HAS. Resultados: 252 pacientes foram submetidos à RYGB no serviço. Setenta e nove (31,3\%) tinham DM2 e 64 tinham HAS associada a DM2. Com relação ao DM2 e à HAS, 37,9\% e 43,7\%, respectivamente, apresentaram remissão total da doença após a operação. Houve redução no pós-operatório do uso de Metformina, insulina/Gliclazida, Propranolol, Losartana e Hidroclorotiazida em $62 \%, 10,1 \%, 100 \%, 26,5 \%$ e 22,8\% dos pacientes, respectivamente. Conclusão: a técnica da RYGB é efetiva na remissão do DM2 e HAS. Mesmo nos casos em que não houve a remissão total das doenças, houve queda significativa no uso de medicamentos usados para o tratamento.
\end{abstract}

Palavras chave: Cirurgia Bariátrica. Diabetes Mellitus. Hipertensão. Obesidade.

\section{REFERENCES}

1. Park S, Lee S, Kim Y, Lee Y, Kang MW, Han K, et al. Altered Risk for Cardiovascular Events With Changes in the Metabolic Syndrome Status: A Nationwide Population-Based Study of Approximately 10 Million Persons. Ann Intern Med. 2019;171(12):875-84.

2. Vlad I. Obesity costs UK economy 2bn pounds sterling a year. BMJ. 2003;327(7427):1308.

3. Shah A, Laferrère B. Diabetes after Bariatric Surgery. Can J Diabetes. 2017;41(4):401-6.

4. Schauer PR, Kashyap SR, Wolski K, Brethauer SA, Kirwan JP, Pothier $C E$, et al. Bariatric surgery versus intensive medical therapy in obese patients with diabetes. N Engl J Med. 2012;366(17):1567-76.

5. Wing RR, Bolin P, Brancati FL, Bray GA, Clark JM, 
Coday $\mathrm{M}$, et al. Cardiovascular effects of intensive lifestyle intervention in type 2 diabetes. $N$ Engl J Med. 2013;369(2):145-54.

6. Owen JG, Yazdi F, Reisin E. Bariatric Surgery and Hypertension. Am J Hypertens. 2017;31(1):11-7.

7. Reisin E, Abel R, Modan M, Silverberg DS, Eliahou $H E$, Modan B. Effect of weight loss without salt restriction on the reduction of blood pressure in overweight hypertensive patients. N Engl J Med. 1978;298(1):1-6.

8. Reisin E, Frohlich ED. Effects of weight reduction on arterial pressure. J Chronic Dis. 1982;35(12):887-91 .

9. Dixon JB, O'Brien PE, Playfair J, Chapman L, Schachter LM, Skinner $S$, et al. Adjustable gastric banding and conventional therapy for type 2 diabetes: a randomized controlled trial. JAMA. 2008;299(3):316-23.

10. Mingrone G, Panunzi S, De Gaetano A, Guidone C, laconelli $A$, Leccesi $L$, et al. Bariatric surgery versus conventional medical therapy for type 2 diabetes. $\mathrm{N}$ Engl J Med. 2012;366(17):1577-85.

11. Schauer PR, Bhatt DL, Kirwan JP, Wolski K, Brethauer SA, Navaneethan SD, et al. Bariatric surgery versus intensive medical therapy for diabetes--3-year outcomes. N Engl J Med. 2014;370(21):2002-13.

12. Ikramuddin S, Korner J, Lee WJ, Connett JE, Inabnet WB, Billington $C J$, et al. Roux-en-Y gastric bypass vs intensive medical management for the control of type 2 diabetes, hypertension, and hyperlipidemia: the Diabetes Surgery Study randomized clinical trial. JAMA. 2013;309(21):2240-9.

13. Ahmad NN, Pfalzer A, Kaplan LM. Roux-en-Y gastric bypass normalizes the blunted postprandial bile acid excursion associated with obesity. Int J Obes (Lond). 2013;37(12):1553-9.

14. American Diabetes Association. Diagnosis and classification of diabetes mellitus. Diabetes Care. 2014;37 Suppl 1:S81-90.

15. Buse JB, Caprio S, Cefalu WT, Ceriello A, Del Prato $S$, Inzucchi SE, et al. How do we define cure of diabetes? Diabetes Care. 2009;32(11):2133-5.

16. Sjöström $L$, Peltonen $M$, Jacobson $P$, Sjöström $C D$, Karason K, Wedel H, et al. Bariatric surgery and longterm cardiovascular events. JAMA. 2012;307(1):5665.
17. Schauer PR, Nor Hanipah Z, Rubino F. Metabolic surgery for treating type 2 diabetes mellitus: Now supported by the world's leading diabetes organizations. Cleve Clin J Med. 2017;84(7 Suppl 1):S47-S56.

18. Rubino F. Is type 2 diabetes an operable intestinal disease? A provocative yet reasonable hypothesis. Diabetes Care. 2008;31 Suppl 2:S290-6.

19. Rhee NA, Vilsbøll T, Knop FK. Current evidence for a role of GLP-1 in Roux-en-Y gastric bypass-induced remission of type 2 diabetes. Diabetes Obes Metab. 2012;14(4):291-8.

20. Osto E, Doytcheva P, Corteville C, Bueter $M$, Dörig C, Stivala $S$, et al. Rapid and body weightindependent improvement of endothelial and highdensity lipoprotein function after Roux-en-Y gastric bypass: role of glucagon-like peptide-1. Circulation. 2015;131(10):871-81.

21. Steinert RE, Feinle-Bisset C, Asarian L, Horowitz M, Beglinger C, Geary N. Ghrelin, CCK, GLP-1, and PYY(3-36): Secretory Controls and Physiological Roles in Eating and Glycemia in Health, Obesity, and After RYGB. Physiol Rev. 2017;97(1):411-63.

22. Cole AJ, Teigen LM, Jahansouz C, Earthman CP, Sibley SD. The Influence of Bariatric Surgery on Serum Bile Acids in Humans and Potential Metabolic and Hormonal Implications: a Systematic Review. Curr Obes Rep. 2015;4(4):441-50.

23. Penney NC, Kinross J, Newton RC, Purkayastha S. The role of bile acids in reducing the metabolic complications of obesity after bariatric surgery: a systematic review. Int J Obes (Lond). 2015;39(11):1565-74.

24. Kohli R, Bradley D, Setchell KD, Eagon JC, Abumrad $\mathrm{N}$, Klein S. Weight loss induced by Roux-en-Y gastric bypass but not laparoscopic adjustable gastric banding increases circulating bile acids. J Clin Endocrinol Metab. 2013;98(4):E708-12.

25. Mingrone G, Panunzi S, De Gaetano A, Guidone C, laconelli A, Nanni $G$, et al. Bariatric-metabolic surgery versus conventional medical treatment in obese patients with type 2 diabetes: 5 year followup of an open-label, single-centre, randomised controlled trial. Lancet. 2015;386(9997):964-73.

26. Hutter MM, Schirmer BD, Jones DB, Ko CY, Cohen 
ME, Merkow RP, et al. First report from the American College of Surgeons Bariatric Surgery Center Network: laparoscopic sleeve gastrectomy has morbidity and effectiveness positioned between the band and the bypass. Ann Surg. 2011;254(3):41020; discussion 20-2.

27. Courcoulas AP, King WC, Belle SH, Berk P, Flum DR, Garcia L, et al. Seven-Year Weight Trajectories and Health Outcomes in the Longitudinal Assessment of Bariatric Surgery (LABS) Study. JAMA Surg. 2018; 153(5):427-34.

28. Thereaux J, Lesuffleur T, Czernichow S, Basdevant A, Msika S, Nocca D, et al. Association Between Bariatric Surgery and Rates of Continuation, Discontinuation, or Initiation of Antidiabetes Treatment 6 Years Later. JAMA Surg. 2018;153(6):526-33.

29. Zhao L, Li W, Su Z, Liu Y, Zhu L, Zhu S. Preoperative Fasting C-Peptide Predicts Type 2 Diabetes Mellitus

Received in: 05/06/2020

Accepted for publication: 27/08/2020

Conflict of interest: no.

Funding source: no.
Remission in Low-BMI Chinese Patients After Roux-en-Y Gastric Bypass. J Gastrointest Surg. 2018;22(10):1672-8.

30. Jakobsen GS, Småstuen MC, Sandbu R, Nordstrand $N$, Hofs $\varnothing D$, Lindberg $M$, et al. Association of Bariatric Surgery vs Medical Obesity Treatment With Longterm Medical Complications and Obesity-Related Comorbidities. JAMA. 2018;319(3):291-301.

31. Hall JE, do Carmo JM, da Silva AA, Wang Z, Hall ME. Obesity-induced hypertension: interaction of neurohumoral and renal mechanisms. Circ Res. 2015;116(6):991-1006.

32. Schiavon CA, Bersch-Ferreira AC, Santucci EV, Oliveira JD, Torreglosa CR, Bueno PT, et al. Effects of Bariatric Surgery in Obese Patients With Hypertension: The GATEWAY Randomized Trial (Gastric Bypass to Treat Obese Patients With Steady Hypertension). Circulation. 2018;137(11):1132-42.
Mailing address:

Giulia Marchetti

E-mail: giu.marchetti95@gmail.com

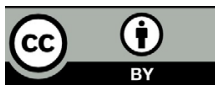

